\title{
Research on the Application of Blockchain Technology in the Field of Corporate Governance
}

\author{
Liyuan Meng ${ }^{1}$, Shaodong Xing ${ }^{1 *}$ \\ ${ }^{1}$ Lanzhou University of Technology School of Economics and Management Lanzhou, China
}

\begin{abstract}
The Annual General Meeting of Shareholders is considered to be a boring and mandatory annual ceremony. At present, its information, forum, decision-making functions, and voting procedures are all flawed. As a new technology, the introduction of blockchain can greatly reduce the cost of shareholder voting and company organization costs, improve the company's decision-making efficiency and the transparency of voting and elections, and effectively solve the problems existing in the current annual general meeting of shareholders. The research in this paper provides an intelligent solution for the traditional inefficiency of corporate governance.
\end{abstract}

\section{INTRODUCTION}

The annual general meeting is one of the places where all shareholders directly supervise the board of directors and major shareholders. Its organization usually makes decisions about the company's major business matters, It also provides an effective way for shareholders to participate in corporate governance. It is very important for both listed companies and shareholders to hold a good annual general meeting of shareholders.

The annual general meeting of shareholders has three main functions: Information function (transmit company information to shareholders), forum function (provide a place for shareholders to discuss and ask questions), decision-making function (make decisions on major business matters of the company). The decision-making function of the annual general meeting is generally regarded as the core function of the annual general meeting. From the perspective of agency theory, the convening of the annual general meeting of shareholders has greatly eased the agency conflict between the company's shareholders and managers. However, some shortcomings of the annual general meeting of shareholders are slowly exposed.

\section{The functional defects of the annual general meeting}

\subsection{Defective information function}

Most annual general meetings are held between three and six months after the end of the accounting period. However, in order to protect the legitimate rights and interests of small and medium shareholders and meet the requirements of regulatory policies, the relevant information for shareholders and investors is not disclosed at the general meeting of shareholders, but is disclosed at a certain time throughout the year. Usually this information is disclosed before the annual general meeting, which means that most of the information disclosed at the annual general meeting has already been known to shareholders.

\subsection{Defective forum function}

The forum function of the annual general meeting provides shareholders with a good opportunity to interact with the management. However, while reviewing the company's development in the last fiscal year and making plans for the company's future development, the annual general meeting lasts for a few hours at most. This means that not all shareholders have the opportunity to ask questions and communicate. It can be seen that the forum function of the annual general meeting of shareholders has not played its role well.

\subsection{Defective decision-making function}

The decision-making function is the most important function of the annual general meeting. However, in the annual general meeting, the attendance rate of small and medium shareholders is relatively low, the enthusiasm for participation is relatively low, and many small and medium shareholders are reluctant to vote. What is causing this?

First, many companies face the problem of high equity concentration, which means that large shareholders may have legal or de facto control rights, which leads to opportunistic behaviors of small shareholders. Regardless of whether the minority shareholders participate in the voting, the voting results are the same. That is to say, in this case, the participation of small and medium 
shareholders in voting has basically no effect on the voting results. On the contrary, the participation of small and medium shareholders in voting will incur corresponding costs and will not affect the voting results. At this time, it is a good choice for them not to participate in voting.

Second, there is a free-riding problem. Shareholder supervision can be regarded as a public good. Since shareholder supervision is non-exclusive and noncompetitive, shareholders cannot prevent other shareholders from benefiting from their supervision. The resulting supervision costs will not affect the interests of other shareholders. Under such circumstances, if the cost of shareholder supervision is not zero, no one is willing to bear the cost of supervision. This free-riding problem leads to an insufficient amount of public goods. The actual level of supervision is lower than the level of supervision that maximizes the collective welfare of all minority shareholders. In addition, when these small and medium shareholders are dissatisfied with the company's development, they can reduce their holdings or even sell their shares, which to a certain extent also reduces the participation of these shareholders.

\section{Procedural deficiencies in election voting}

In the annual general meeting of shareholders, shareholders can exercise their voting rights through onsite voting, proxy voting (a voting method in which shareholders entrust their voting rights to representatives), mail voting, and online voting. For small and medium shareholders, remote voting through proxy voting, mail voting, and online voting is a common way for them to participate in the annual general meeting. Because these voting methods do not require these shareholders to attend the annual general meeting in person, thereby reducing the voting cost of shareholders. Increased the participation of shareholders to a large extent.

However, can the remote votes of these shareholders be passed to the company correctly, and can the company receive the votes of these shareholders and count them? Each shareholder who voted at the annual general meeting can verify whether the vote has been effectively recorded and counted by the company after the general meeting. Some boards of directors knew the result of the vote even before the meeting. Therefore, it is necessary to question its voting results. Although remote voting is now the most commonly used voting tool, it still does not provide shareholders with transparency and evidence that they actually exercised their votes ${ }^{[1]}$.

\section{Blockchain and smart contracts}

The blockchain can be seen as a distributed shared ledger and database, which can record transactions between parties in an effective, verifiable and permanent manner. In a blockchain system running on a decentralized peerto-peer network, information is stored on a public ledger (public chain) or private ledger (private chain) and contains all the transactions performed. Since the number of transactions is always increasing, blocks with these transactions will continue to be added to the ledger. In contrast to the classic ledger that overwrites the previous records, every new transaction is added to the blockchain system. These blocks are added in a linear and chronological manner, so they are called "blockchains". The ledger contains every transaction that was made in the blockchain in the past. Miners add blocks to the blockchain, and they verify transactions by competing with complex code to solve problems. The ledger is replicated to many of the same decentralized databases, and when changes are made to one of them, these databases are also updated at the same time. In the absence of a trusted intermediary, the verification of the transaction relies on the consensus reached between all participants or nodes, which includes the verification of each transaction and the broadcasting process of new blocks to ensure its legitimacy and add it to In the ledger. Because each block in the blockchain contains the record of the previous block to ensure the immutability of the transaction, if you want to change a transaction, you need to modify not only the relevant block, but also all the following blocks. Therefore, once a block is completed, it is considered immutable and enters the ledger permanently. It can be seen that blockchain technology can promote transparency and trust between the two parties ${ }^{[2]}$.

Blockchain can be used for a variety of applications, including smart contracts. Smart contracts can monitor the negotiation conditions and automatically make payments as soon as these conditions are met. Think of a smart contract as a grammar that can use blockchain technology to enter, execute, and enforce agreements (some or all of the terms). The legal terms are replaced by the grammar in the smart contract executed in the blockchain, so it can no longer be modified, thus eliminating the uncertainty of the possibility of a party wishing to renegotiate the contract. All conditions are included in the smart contract. Once these conditions are met, it will be automated. It can overcome moral hazard issues such as strategic breaches and can significantly reduce the cost of verification and execution $^{[3]}$.

\section{Blockchain technology to solve the defects of the annual general meeting of shareholders}

Under the blockchain technology, can the problems existing in the current annual general meeting of shareholders be solved? The answer is obvious. The issue of the timeliness of information transmission in the annual general meeting of shareholders, the issue of forum function failure, the issue of low decision-making transparency, and the issue of voting credibility are all directly related to the advantages of blockchain technology.

First of all, under the blockchain technology, the approved company decisions can be placed in the blockchain at any time, so that the shareholders of the company can know the company information at any time, which improves the defect of information delay in the past and reduces the cost of information transmission, this greatly solves the problem of the timeliness of information 
transmission of the current annual shareholder meeting.

Secondly, with the introduction of blockchain technology, theroved. In previous annual shareholder meetings, there are actually very few shareholders who can actually participate in the forum, and small and medium shareholders have fewer opportunities to participate. However, under the blockchain technology, the function of the forum is likely to change. Blockchain can provide a discussion platform for shareholders and board members, which will remain digital, for example in the form of video chat. All shareholder questions on the platform are included in the blockchain, and the board's answers are also included, which greatly increases the transparency of the forum. Therefore, blockchain technology may actually enhance the forum function of the annual shareholder meeting.

Third, the introduction of blockchain technology can help solve the problems of slow decision-making and high cost at the annual general meeting of shareholders. At present, shareholders' decision-making in the annual general meeting of shareholders is often too slow and may be useless. At the same time, it also faces defects such as high cost and time-consuming. Blockchain applications can eliminate this inefficiency and enable them to directly submit proposals to management, etc, and vote and make decisions in a relatively short period of time. This will greatly improve the inefficient decision-making function of the current annual shareholder meeting. At the same time, blockchain technology has greatly reduced the decision-making costs of companies and shareholders. The improvement of decision-making efficiency can reduce the company's decision-making cost to a large extent, and the company does not need to spend a lot of resources to organize the annual shareholder meeting with the support of blockchain technology, which also saves the company's cost. Similarly, blockchain technology also reduces the cost of shareholders. Blockchain provides shareholders with a reliable and accessible way to participate, thereby reducing the cost of shareholder participation and increasing the enthusiasm of shareholders to participate in company decision-making. Shareholders can Vote on one or more voting items from your desk in a short period of time $\mathrm{e}^{[4]}$.

Finally, under the blockchain technology, the procedural defects of the annual shareholder meeting will be improved. Remote voting has greatly reduced the transaction costs of shareholders in the past, but the transparency and credibility of this method is not high, and shareholders will still question this. Especially in the Chinese stock market, it is very common for large shareholders to infringe on small shareholders, large shareholders and management teamed up to hollow out listed companies, to a large extent, it is because small shareholders and ordinary shareholders cannot directly participate in company voting and cannot participate in corporate governance better. Blockchain technology will allow rapid and safe recording of votes, simplify the historically labor-intensive and decentralized proxy voting process, improve the efficiency and fairness of voting, and greatly increase the enthusiasm of all shareholders to participate in corporate governance, it also solves the corporate governance problems caused by the proxy voting system ${ }^{[5]}$. The research report of the CSD Working Group on DLT' outlines the requirements for shareholder proxy voting in a blockchain, and determined the following steps:

Table1. Proposed Process Flow of the CSD Working Group on DLT

\begin{tabular}{|c|c|c|}
\hline \# & Step & Description \\
\hline 1 & $\begin{array}{l}\text { Initialization } \\
\text { and notification } \\
\text { of the meeting }\end{array}$ & $\begin{array}{l}\text { Set the meeting date and record } \\
\text { date on the distributed ledger, and } \\
\text { the meeting agenda and } \\
\text { supplementary materials can be } \\
\text { stored in the distributed ledger. }\end{array}$ \\
\hline 2 & $\begin{array}{l}\text { Ownership } \\
\text { Record } \\
\text { Loading }\end{array}$ & $\begin{array}{l}\text { Intermediaries load a list of } \\
\text { beneficial owners and ownership } \\
\text { records at the voting record date } \\
\text { into the blockchain. }\end{array}$ \\
\hline 3 & $\begin{array}{l}\text { Voting Right } \\
\text { Allocation }\end{array}$ & $\begin{array}{l}\text { Issue tokenized voting rights to all } \\
\text { shareholders who are eligible to } \\
\text { vote on the record date, taking } \\
\text { into account voting restrictions, } \\
\text { types of shares with different } \\
\text { voting rights, etc. }\end{array}$ \\
\hline 4 & $\begin{array}{l}\text { Voting Party } \\
\text { Authentication }\end{array}$ & $\begin{array}{l}\text { The shareholder identity } \\
\text { verification is carried out through } \\
\text { the method supported by the local } \\
\text { system, but the identity } \\
\text { verification certificate must be } \\
\text { stored on the blockchain. }\end{array}$ \\
\hline 5 & $\begin{array}{l}\text { Proxy } \\
\text { Assignment }\end{array}$ & $\begin{array}{l}\text { The possibility of transferring } \\
\text { voting rights from shareholders to } \\
\text { designated agents. }\end{array}$ \\
\hline 6 & Voting & $\begin{array}{l}\text { Shareholders or proxies use their } \\
\text { tokenized voting rights to issue } \\
\text { voting instructions. }\end{array}$ \\
\hline 7 & $\begin{array}{l}\text { Meeting } \\
\text { Management }\end{array}$ & $\begin{array}{l}\text { Shareholders must be able to see } \\
\text { whether their voting instructions } \\
\text { are included in the voting results, } \\
\text { and their actions should be } \\
\text { traceable to their source. }\end{array}$ \\
\hline 8 & $\begin{array}{l}\text { Post-meeting } \\
\text { actions }\end{array}$ & $\begin{array}{l}\text { Any events that occur } \\
\text { independently of other events } \\
\text { after the meeting. When the } \\
\text { voting results are announced, the } \\
\text { anonymity of the beneficial } \\
\text { owners and the confidentiality of } \\
\text { their actions should be } \\
\text { guaranteed. }\end{array}$ \\
\hline
\end{tabular}

Their research is very helpful to solve the shortcomings of the current voting system.

\section{CONCLUSION}

This article takes shareholders' participation in the annual general meeting of shareholders as the entry point. First, it conducts an in-depth analysis of the defects in the current annual general meeting of shareholders and the voting procedures; secondly, introduces blockchain technology and makes a brief introduction to blockchain technology and smart contracts. Finally, it is analyzed that blockchain technology can solve the problem of defects in the annual 
general meeting of shareholders. The study found that the application of blockchain technology can greatly reduce shareholder voting costs and company organizational costs, improve the company's decision-making efficiency and the transparency of voting and elections, and provide new solutions to classic agency problems in corporate governance.

\section{References}

1. David Yermack. Corporate Governance and Blockchains [J]. Review of Finance, 2017, 21 (01): 731.

2. Yang Runhui. Application of blockchain technology in the field of financial sharing $[\mathrm{J}]$. Finance and Accounting Monthly, 2020 (09): 35-40.

3. Wang Wenjun. A functionalist review of the technicality and legitimacy of financial smart contracts [J]. Financial Developmen t Research, 2021 (03): 61-68.

4. $\mathrm{Gu}$ Hongyu. Analysis on the potential impact of blockchain technology on the future accounting and auditing industry $[\mathrm{J}]$. Chinese Certified Public Accountant, 2020 (03): 81-85.

5. Zhao Yuan. How does blockchain technology affect corporate governance? [J]. Pay taxes, 2020, 14 (05): 201-202. 